\title{
Political will and cash 'needed to speed up removal of landmines'
}

Boston. New technologies and strategies could speed up removal of the more than 100 million landmines that remain buried around the world, according to two reports issued last month. But the initiatives need a greater injection of both political will and finance to succeed.

Landmines kill or maim 25,000 to 30,000 people a year, 80 per cent of them civilians, say the reports. There is a pressing need for a single high-level intergovernmental agency to focus global efforts on implementing new technologies for demining, says one report written by Kosta Tsipis. The author is a physicist at Massachusetts Institute of Technology (MIT), and the report is based on a 'brainstorming workshop' held last August in Cambridge, Massachusetts.

Paul Horowitz, a physicist at Harvard University, is lead author of the second report, New Technological Approaches to Humanitarian Demining. This is based on a study conducted by the JASON defence advisory group at the request of the Defense Advanced Research Projects Agency.

"Demining removes about 100,000 mines annually, but for every mine removed about 20 new mines are emplaced," says the JASON report. "The problem is only getting worse."

Hand-held metal detectors used for demining cannot distinguish between mines and other metal objects buried in the soil. So the task is perilous and time-consuming with false alarms outnumbering genuine detections, sometimes by 1,000 to one.

"People have become discouraged by the slow and dangerous nature of demining," says Tsipis. He organized the MIT work- shop, and invited a group of scientists known for technical innovation, in the hopes of making the process safer, more efficient and less costly. "We came out of the workshop encouraged by the promising technologies that can be brought to bear on the problem."

The first step, he says, is to determine the precise characteristics of landmines to make detection easier. "We still do not know the physical and chemical properties of landmines." Measurements are needed to establish their acoustic, microwave and infrared 'signatures'.

A combination of new technologies could speed up demining by a factor of five, according to the MIT report. These are a metal detector called the "interdigitated winding magnetometer"; an "air knife" that can dig up mines in seconds, and the explosive Lexfoam which can blow up mines in situ. Tsipis is thinking of organizing a workshop this year to see how these devices might be used in Laos to clear the millions of unexploded 'bomblets' dropped during the Vietnam War.

Both reports recommend various methods to help to identify mines, including nuclear quadrupole resonance, X-ray backscatter techniques and electronic vapour detectors. But such technologies need further development.

Within five years, detectors mounted on robotic vehicles could enhance demining capabilities 100 - to 1,000 -fold, the MIT report predicts. But it adds that no single approach will solve all demining problems.

Although the JASON study was confined to technology assessment, Tsipis and his colleagues also addressed political concerns.

\section{BSE inquiry could prompt censure vote}

Paris. The European Parliament may be asked to bring a motion of censure against the European Commission over its handling of the bovine spongiform encephalopathy (BSE) crisis. The use of this power would be unprecedented in the history of the European Union, and could result in the dismissal of individual commissioners.

The censure motion is proposed in a draft report of the conclusions of the parliament's inquiry into the crisis by Manuel Medina Ortega, a Spanish socialist member of the parliament, and rapporteur of the inquiry. The report alleges that the commission had a policy of "minimizing the problem [of BSE] that could have given rise to a policy of disinformation, always with the aim of preventing perturbation of the beef market".

This is one of a long list of allegations in the 26-page report of "negligence" against the commission, the Council of Ministers and the UK government many of which had already been made during the course of the inquiry (see Nature 384, 8; 1996 \& 385, 6; 1997). In particular, the report strongly criticizes the failure of the UK government to ban exports of potentially contaminated meat and bone meal after it had decided to ban its use in ruminant feed at home.

The parliament's inquiry is due to end later this month.

Declan Butler

\section{IMAGE UNAVAILABLE FOR COPYRIGHT REASONS}

Unwelcome legacy: better demining methods could reduce the number of landmine victims.

Tsipis argues that a central agency whether the US government, United Nations or European Union - is required to coordinate efforts and raise and allocate funds for new technologies. Such an agency would rely on a science advisory board to provide new information and to serve as a link between academics and industry.

"Today, there are dozens of nongovernmental organizations (NGOs) like Red Cross and Care working separately, which doesn't get you anywhere," Tsipis says.

The call for a central agency is not likely to receive a universal welcome. One US defence official says: "There already is a central agency - the Humanitarian Demining Technologies program run by the Department of Defense (DoD), which has tested more than 30 pieces of demining equipment since it began in 1995." He also disputes the claim that money is the chief stumbling-block: "Technology is the problem, not money."

Tsipis praises the DoD programme for its contributions to technology development and testing. But he adds that a higher-level agency is needed "to make decisions about what technologies will be used and where the money will come from". The United States has appropriated $\$ 20$ million to the task for 1997, and this may be enough for research and development, he says. "But the crunch will come when you need hundreds of millions of dollars for demining on a large scale."

Steve Nadis 